$\xi=-1$

\title{
Water Bodies Area Extraction from Resourcesat-2 Awifs Image Using Automated Algorithm, Visakhapatnam District, Andhra Pradesh, India
}

\author{
K. M. Ganesh ${ }^{1 *}$, P.A.R.K.Raju ${ }^{1}$, N. Gopalakrishna Murthy ${ }^{2}$, N.Srinivasu ${ }^{3}$ \\ ${ }^{I}$ Department of Civil Engineering, SRKR Engineering College, Bhimavaram, Andhra Pradesh, India-534204 \\ ${ }^{2}$ Department of Information Technolog, SRKR Engineering College, Bhimavaram, Andhra Pradesh, India-534204 \\ ${ }^{3}$ Department of Electrical and Electronics Engineering, SRKR Engineering College, Bhimavaram, Andhra Pradesh, India-534204 \\ *Corresponding author E-mail:lakshmimanojna.k@gmail.com
}

\begin{abstract}
Irrigation water was supplied to supplement the water available from rainfall, So the purpose of crop production of application of water to soil is the Irrigation. Due to lack of amount and timing of rainfall, to the moisture requirement of crops and irrigation, It is necessary to meet the needs of food and fibbers, So the raise crops is essential in many area of the world. Water features composed of all surface water features viz. reservoirs, tanks \& ponds, beels, oxbow lakes, derelict water and brackish water, which are the function of intensity of rainfall, rainfall amounts etc. over season/a year. The mapping, monitoring of dynamics of surface water bodies were acquire by satellite sensors through synoptic and dynamic coverage of earth surface at frequent intervals. In FCC water bodies appear as different hues depending on their physical characteristics such as depth of water (bottom reflection), turbidity, etc. Water appears dark due to which absorbs all infrared radiations. This helps in easy contrast distinction between water and land in near-infrared band. Mapping, monitoring and inventory of water features over wide areas by Satellite data is a reputed proficiency for creation of dynamic databases. Our present area of interest includes an automatic approach to capture the water body from a Resourcesat-2 AWiFS (Advanced Wide-Field Sensor) imagery using a Automated Algorithm for extraction of surface water bodies model. The dynamics of surface water bodies in study on geospatial analysis of the evaluation of water feature sheets for the month of April, 2018 of the study area. The water features information was generated on geospatial database from the Resourcesat-2 AWiFS image by using bands of 1.55- 1.70 $\mu \mathrm{m}$ (SWIR), 0.77-0.86 $\mu \mathrm{m}$ (NIR), 0.62-0.68 $\mu \mathrm{m}$ (Red) and 0.52-0.59 $\mu \mathrm{m}$ (Green) for the estimation of the water spread area. The Water Spread Area (WSA) calculated for each is 11304 ha [1] and [2].
\end{abstract}

Keywords: Surface Water Bodies, Water Spread Area, Remote Sensing and G.I.S.

\section{Introduction}

Water is one of the primary elements (others being air, fire, sky and the earth), which preserves the wholeness of the natural environment. It is very important for the social and economic development. There are many natural resources, but water is the major inexhaustible renewable resource. Water is a very vital part of all the life processes. It is the greatest responsibility of those, who manage, improve and use water, to control, assess and develop, consume and manage the water resources [3].

\subsection{Water Resources of India}

Water resources of the country in inshore include reservoirs, lakes, rivers, canals, tanks and ponds, and brackish water. The total water features occupies all area of about 7 M.Ha. excluding canals and rivers. In view of the canals and rivers, In the country the total length of the canals and rivers occupies 17 percent and capture the 31.2 thousand $\mathrm{km}$ with total length in Uttar Pradesh. In the stipulated time intervals satellite sensors can capture the existing situations of surface water features which facilitate to take the effective measures to improve the situation. It is also been observed that the satellite data utilization rapidly extended to other areas also.

This studies gives an approach to evaluate the water feature from a Resourcesat-2 AWiFS resemblances using a Automated Algorithm for extraction of surface water feature model.

The remotely sensed images having typical spectral reply of water which make possible to accurate identificate and depiction. So that, Major effort in mapping surface water bodies at national level using multi-spectral data from multi-date IRS LISS III/AWiFS images by the growth of automatic feature extraction techniques. To creation of dynamic databases for monitoring, mapping and inventory of water features of satellite data using is a popular technique. The aim of present study is automatic delineation of water bodies [1].

\section{Materials and Methods}

The area of study occupies a main area in the coastal districts of Andhra Pradesh. The study area is enveloped by Eastern Ghats and Bay of Bengal. Visakhapatnam is the district headquarters. The district stretched out between $17^{\circ}-15^{\prime}$ and $18^{\circ}-32^{\prime}$ Northern latitude and $18^{\circ}-54^{\prime}$ and $83^{\circ}-30^{\prime}$ in Eastern longitude. It is bounded on the North partly by the Orissa State and partly by Viziana- 
garam District, on the South by East Godavari District, on the West by Orissa State and on the East by Bay of Bengal [4]. The study area stretches about $132 \mathrm{~km}$ in coastline. The monthly rainfall span from nil in January to 207.5 in October and $1116 \mathrm{~mm}$ is the average annual rainfall of the study area.(Figure 1.)

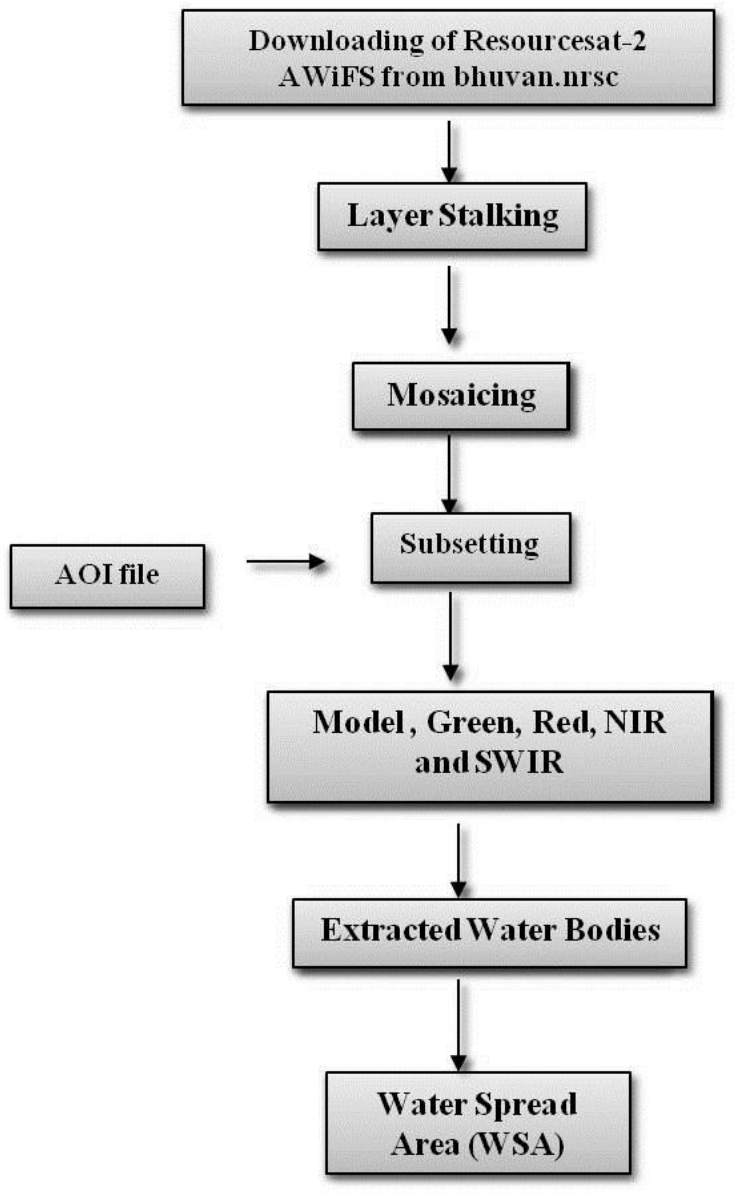

Figure 2: Overview of Methodology

\subsection{Hydrogeology}

The oldest Archaens to fresh alluvium is the varieties of geolog ical formations are the underlain of the study area. Khondalites and Charnockites are being the Archaean group of rocks of Eastern Ghats super group. The sandstones of gondwanas which are mentioned by small area. Along the rivers had covered by fresh alluvium. The lineaments which were headed towards the NE-SW, NW-SE and ENE-WSW in the study area.

\subsection{Geomorphology}

The northern hilly terrain with valleys, alluvial coastal plains and middle pediplains are the three regions can be geomorphologically classified in the study area. $900 \mathrm{~m}$ amsl is the average altitude of hills. The weathered formations overlain by valley fill areas in the Araku and Paderu areas having high permeability and high infiltration. The Tandava- Varaha-Sarada-Gosthani river basins which consists hard rock terrain. The Khondalite outcrops has particularly developed with Pediment, whereas in the charnockite outcrops, it is not extensively developed [4]. The Figure 2 illustrates the overall methodology for the evaluation of the water features.

\subsection{Data used for Study}

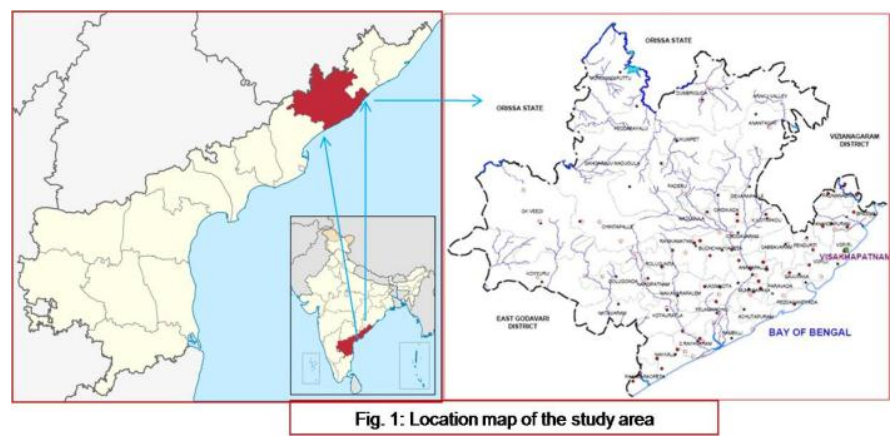

The main source of satellite data for monitoring variations in water spread are through the missions of Resourcesat-2, RISAT -1 of Indian Remote Sensing (IRS). Various sensors are used in extracting the satellite data, they are listed in the table below [5].

\begin{tabular}{ccc} 
& Table: 1 & \\
\hline Satellite-Sensor & Spatial Resolution & Repetivity \\
Resourcesat-2 & $56 \mathrm{M}$ & 5 Days \\
AWiFS & $23 \mathrm{~m}$ & 24 Days \\
$\begin{array}{c}\text { Resourcesat-2LiSS } \\
\text { III }\end{array}$ & 2 & 2 \\
\hline
\end{tabular}

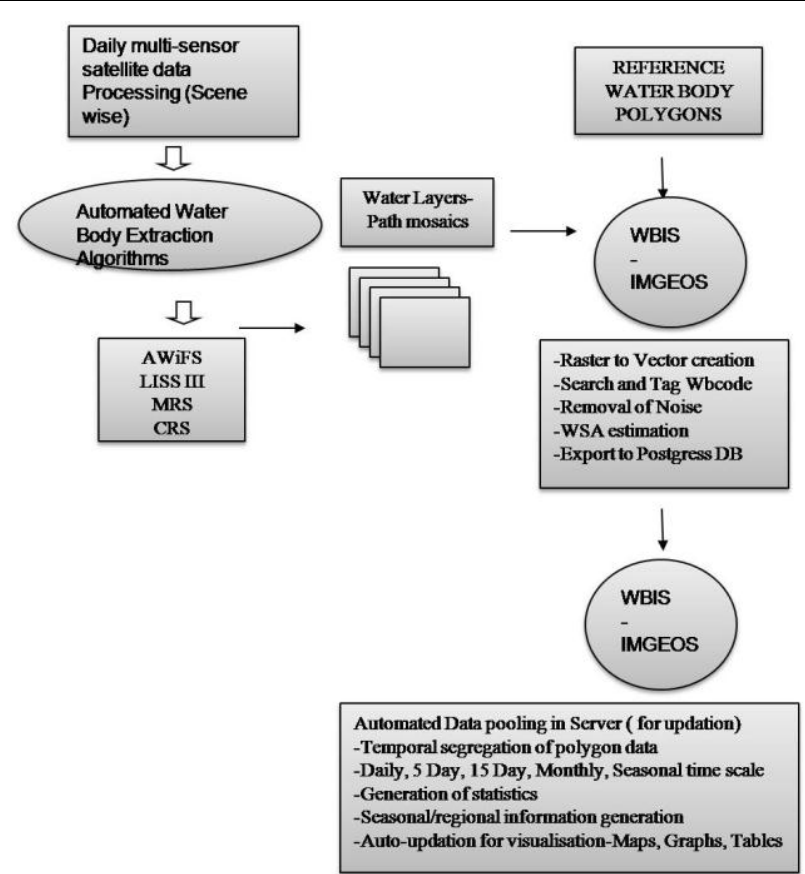

Figure 3 . Process flow chart of Water Bodies Information System

Table: 2

\begin{tabular}{ccc}
\multicolumn{3}{c}{ Table: 2} \\
Year & Month & Source of Satellite Data \\
2016 & Dec, 2016 & Resourcesat -2 AWiFS \\
\hline
\end{tabular}

\subsection{Water Bodies Information System (WBIS)}

Water Bodies Information System (WBIS) is developed using web technologies like Vue JS, Leaflet and eCharts for data visualization and map elements. Raster data is automatically pooled from time-series water layers into a PostGIS enabled Postgres database. Java script and REST APIs are provided using node.js. and Cassandra for generating the statistics of a individual water body, regional (River Basin, River Subbasin, State, District) Mapnik was used as rendering Engine [5]. Process flowchart of WBIS are shown in Figure 3. 


\section{Results and Discussions}

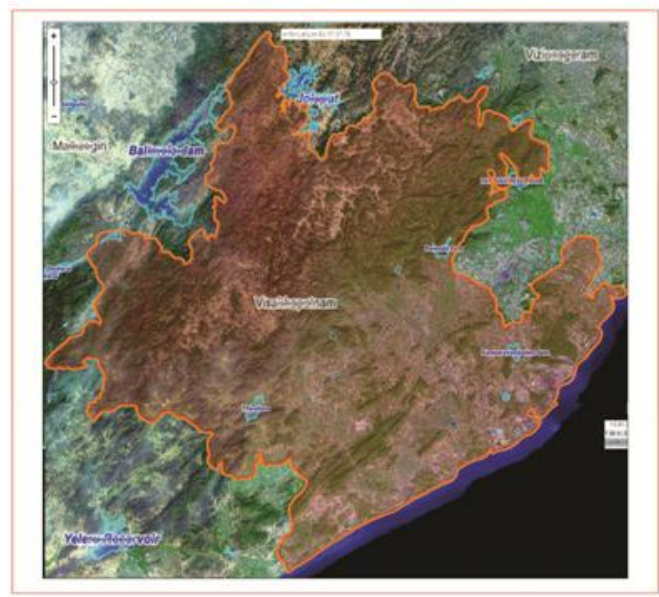

Figure 4 : District boundary layer of area of interest.

By the Analysis of spatial temporal satellite derived water bodies information of Visakhapatnam district, Results acquired from the Model framework for the evaluation of surface water features with the resourcesat-2 image of Visakhapatnam of Andhra Pradesh by the observation of the study. By the images water feature area acquired which is made from the satellite deliberation. Using Resourcesat-2-AWiFS, water feature sheets was determined by the model for evaluation of water feature information of the study area. Surface water features has been analysed by its focal point.

\subsection{Sub Setting of Study Area for Water Extraction}

The area of interest was subset by using a study area shape file to clip the required area by discussing in the methodology section. Figure 4 shows the district boundary layer of area of interest.

\subsection{Extraction of Water Bodies from Satellite Image}

Extraction of water features from the Resourcesat-2 image for using the model shown in methodology. The Figure 5 shows that the extracted water bodies layer for the Visakhapatnam district of Andhra Pradesh

The water spread are of the single water features as illustrated in Figures 5 and 6 . Application of the new model the total water spread area of the study area is 11304 ha. Pixel wise analysis has made for the identification of water and non water features with the analysis of model [1].

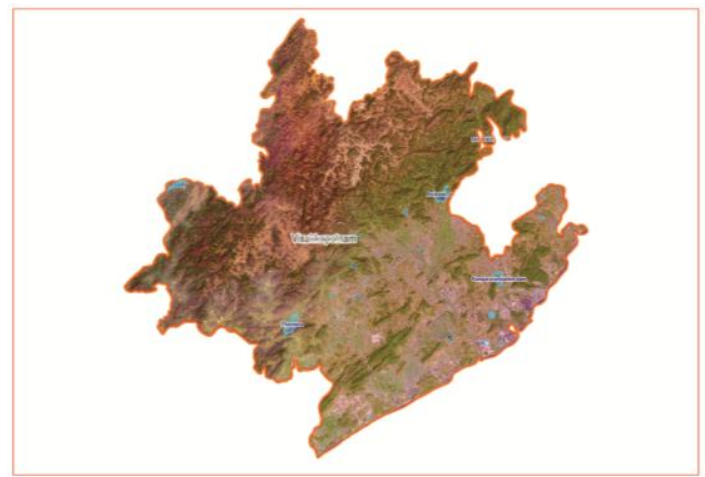

Figure 5 : Subsetting of area of interest

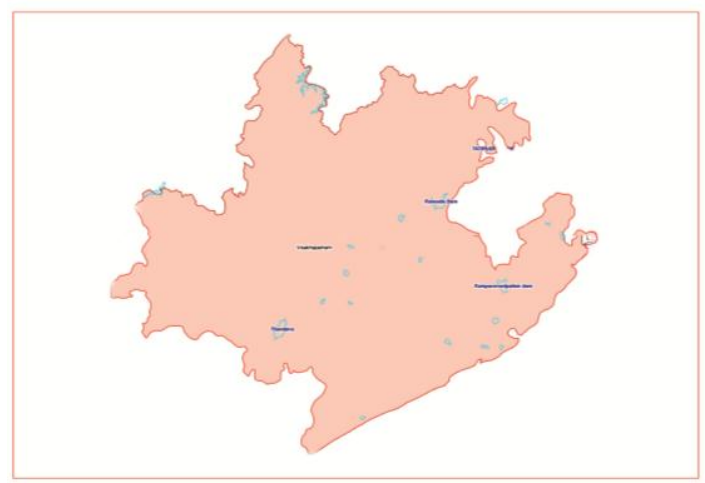

Figure 6 : Extraction of water layer from Satellite image

\section{Conclusions}

In the evaluation of surface water features, analysis and information with the G.I.S. application and the remote sensing mechanism are very serviceable. In April month 2018 the water spread area was analyzed. During this by size as observed from satellite data and aggregated WBA in single class was derived by satellite derived total WBA etc. The total water spread area of Visakhapatnam is 11304 ha. Total number of water bodies in Visakhapatnam district is 1895 .

\section{Acknowledgement}

Authors would like to thank to the Principal and Management of S.R.K.R.Engineering College (Autonomous), Bhimavaram, W.G.District, Andhra Pradesh, India for providing support and encouragement to carry out the study.

\section{References}

[1] Ganesh Mehar, K., et.al., Assessment of surface water bodies using automated algorithm, West Godavari district, A.P., India, (2017), vol.7, 89-94.

[2] Kshitij Mishra and P. Rama Chandra Prasad, "Automatic Extraction of Water Bodies from Landsat Imagery Using Perceptron Model”, Journal of Computational Environmental Sciences, Vol. (2015) Article ID 903465.

[3] S. Subramaniam, A.V. Suresh Babu and P.S. Roy, "Automated Water Spread Mapping Using ResourceSat-1 AWiFS Data for Water Bodies Information System". IEEE Journal of Selected Topics in Applied Earth Observations and Remote Sensing, vol.4, pp. $205-215,2011$.

[4] D. Mohanta, Ground water brochure, Central Groundwater board, (2013).

[5] NRSC Document. "Satellite derived Information on Water Bodies (WBA) and Water Bodies Fraction (WBF)". NRSC SDAPSA-RSAA-(Feb 2014)-TR-580. 